\title{
TELEVISIONES ECONÓMICAS EN ESPAÑA
}

\section{ECONOMIC TELEVISIONS IN SPAIN}

\author{
AUTORA \\ Elvira Calvo \\ Facultad de CC de la Información. Universidad Complutense. Madrid.(España). \\ ecalvogu@ccinf.ucm.es
}

\section{RESUMEN}

En España, la popularización del sector financiero en la década de 1980 trajo consigo una proliferación de publicaciones especializadas en información económica. En 1994 aparece Radio Intereconomía que actualmente se ha convertido en un referente histórico. La especialización ha llegado a la televisión gracias a los cableoperadores y las plataformas digitales, donde conviven dos modelos de televisión económica en España: Bloomberg TV e Intereconomía TV. Con diferentes planteamientos empresariales y grandes dificultades, ambas están logrando hacerse un hueco en el mercado audiovisual español.

\section{PALABRAS CLAVES}

Información económica -Televisión - Canal temático - Bloomberg - Expansión TV

\section{ABSTRACT}

In Spain, the popularization of the financial sector in the decade of 1980 brought I obtain a proliferation of publications specialized in economic information. In 1994 it appears I remove Intereconomy that nowadays has turned into a historical modal. 
The specialization has come to the television thanks to the cableoperadores and the digital platforms, where there coexist two models of economic television in Spain: Bloomberg TV and Intereconomy TV. With different managerial expositions and big difficulties, both they are managing a hollow to be done on the audio-visual Spanish market.

\section{KEY WORDS}

Economic information - Televisión - Thematic channel - Bloomberg - Expansion TV

ÍNDICE

1. Introducción

2. Metodología

3. La información económica audiovisual en España

4. Andanzas y avatares de una televisión económica

4.1. Conexión Financiera (1997-98)

4.2. Expansión TV (1998)

5. Conclusiones

6. Bibliografía

\section{Introducción}

El periodismo económico constituye posiblemente la plasmación más clara de la continua tendencia hacia la especialización que ha venido desarrollando la información en España. La co-existencia de varios diarios económicos, la proliferación de semanarios financieros, y la buena acogida de Intereconomía Radio parecían haber abonado el terreno para la existencia en nuestro país de una, o dos, 
televisiones netamente económicas, Bloomberg TV y Expansión TV. Realmente resulta sugestivo abordar el análisis de estos casos, en especial el segundo por su condición de "netamente española", ya que aúnan lo que parece ser la información más complicada, la economía, y el canal más difícil, la televisión. Resulta paradójico calificar a la televisión como el canal más difícil. La televisión es el medio de comunicación de masas por excelencia. Es audiovisual. Imagen y sonido combinados y sincronizados de forma interdependiente. La coordinación simultánea de imágenes visuales, acústicas y verbales es la base del lenguaje audiovisual, que nos permite comprender la representación de la realidad. Informa, entretiene y forma. Resulta, realmente, muy difícil hablar 24 horas de economía en televisión.

La coexistencia de dos canales temáticos financieros en España rompió la idea de que la información económica no tenía cabida en un medio audiovisual. Tradicionalmente, los profesionales consideraban que la televisión era un medio poco apropiado para transmitir este tipo de noticias, en primer lugar, por las propias limitaciones estructurales y de lenguaje, pero también por la poca aceptación que tenía entre los telespectadores. En todas las mediciones de audiencia de un diario televisado, el índice caía en los minutos dedicados a economía, y sin embargo subían espectacularmente cuando se iniciaban los deportes. Cabe preguntarse si era una pescadilla que se muerde la cola: a la gente no le interesaba la economía porque no hablaban de ella en televisión o la televisión no hablaba de economía porque consideraba que a la gente no le interesaba. Lo cierto es que la información sobre finanzas y empresas no interesó en España hasta casi finales de la década de los años 80 .

La información económica puede ser muy complicada por el lenguaje que utiliza, la escasa cultura económica de la audiencia general y por su difícil tratamiento en un medio como la televisión. Sin embargo, hoy, ningún canal generalista puede permitirse el lujo de excluir las noticias económicas más importantes. 


\section{Metodología}

La metodología seguida para la elaboración de este artículo se basa en el seguimiento de los canales temáticos especializados en economía durante los últimos años. Al centrarse básicamente en la trayectoria del canal español, ha sido posible la realización de entrevistas personales con los directivos de los canales estudiados. Por último, también ha sido fundamental el seguimiento del tema en los medios de comunicación.

Las principales fuentes de información a las que se ha recurrido para la elaboración de este trabajo han sido, en primer lugar, el visionado de los canales objeto de estudio, Bloomberg TV y Expansión TV y, en segundo lugar, las entrevistas personales $\mathrm{y}$ en profundidad realizadas a los directores y redactores jefes de los canales. Asimismo, ha sido fundamental la consulta de bibliografía y la revisión de textos de autores especializados y publicaciones de la Asociación de Periodistas de Información Económica (APIE).

Por último, Internet ha sido, sin duda, una fuente inagotable, constante y actualizada. Mucho se ha escrito sobre información económica como especialización periodística, pero muy poco sobre su proyección en el medio televisión. A destacar, la nula bibliografía sobre televisiones españolas especializadas en economía, cuyo análisis conforma mi mayor aportación.

\section{La información económica audiovisual en España}

El tirón de la prensa económica en la década de los 90 ayudó al aumento de la información económica en los medios audiovisuales españoles, más en radio que en televisión. Las emisoras, como las televisiones, mejoraron sus secciones de economía y además crearon programas específicos sobre el tema. Ante la demanda de profesionales expertos, muchos redactores iniciaron así su especialización, un reto 
que exigía, además de enfrentarse al difícil lenguaje económico, solventar los problemas intrínsecos del propio medio. El concepto se amplía con el desarrollo de las nuevas tecnologías con la aparición de portales financieros.

Como señalaba Balsebre (1994:57), la radio, más ágil que la televisión, ha creado espacios de debate y opinión, en forma de tertulias, y otros de participación del oyente, al estilo de los consultorios. Desde mediados de los años 80, la información económica se ha abierto camino en la radio y los informativos radiofónicos ya cuentan con una importante sección de economía, una materia que era considera como la convidada de piedra, la que se reservaba para el final y la que sirvió para dar lustre a los servicios informativos de RNE. A partir de este ejemplo, todas las emisoras mejoraron su sección de economía y crearon también programas específicos. Las radios comerciales aprovecharon el tirón. Las conexiones con la bolsa se fueron ampliando y en ocasiones llegaron a convertirse en pequeños coloquios en los que se utilizaba un lenguaje muy accesible para todo tipo de público. Fueron, y son, auténticos espacios económicos que, generalmente, están patrocinados por una sociedad de valores y bolsa u otra entidad financiera.

En cuanto a la información económica en televisión hay que remontarse a 1974 cuando nace la Asociación de Periodistas de Información Económica (APIE)-, para vislumbrar un flujo de información económica que en el medio televisivo empieza a ser importante dos años después, con la crisis del petróleo y las reivindicaciones sindicales (Piedrahita, 1998: 72). Con la consolidación de la democracia, la economía pasa a un primer plano. Nacen los diarios económicos y la expectación por la información financiera. Como en la radio, también la información económica comienza a ganar presencia en televisión durante los años 70 y 80 , siempre un poco más rezagada. Se consolida la sección en TVE y, en los 90, con la aparición de las televisiones privadas, se acortan distancias. Aparecen los primeros programas especializados en la materia pero con escasos resultados, la televisión era un medio para entretener. En general, eran programas de públicos bastante restringidos y que 
se emitían en horarios de audiencias específicas (Cebrián, 1998:97). Como indica Cebrián, estos programas aparecían con tres niveles de divulgación: para el gran público, para determinados telespectadores preocupados por aspectos específicos de la economía y para expertos.

Los programas de información económica abarcan un espectro amplio de temas sobre economía en general, mundo empresarial, mundo de los negocios; se seleccionan aquellos que puedan ser de mayor interés para la audiencia y de clara exposición por televisión. Temas como el paro, la inflación, subida de impuestos, subida de precios, tendencias empresariales referidas a diversos sectores de producción y servicio son de frecuente presencia en los programas centrados en economía. Son programas de duración media, de aproximadamente 30 minutos, semanales o diarios (salvo los fines de semana).

Los programas pioneros en economía fueron en la monopolizada TVE que emitió Cuarto y mitad (1976-77), Mas-Menos (1977), Tribuna de la economía (1978-81); El canto de un duro (1978 en el segundo canal), y La Bolsa y la vida. Coincidiendo con estos programas, TVE consolida su sección de economía de la que han surgido periodistas como Javier Gilsanz o Carmen Sastre. Otros programas fueron Campo y mar, Agrosfera (1997), La bolsa y el dinero (2000-01), Impulso, dirigido por Luis Aparicio y espacios patrocinados como Emprendedores y España innova, de dos minutos de duración que se emitían por La 2, un día por semana, y a las 20:55 horas.

De las privadas, destaca Antena 3 con su programa Noticias de economía (1990-92); en Canal + iniciaron un pequeño boletín de cuatro minutos en horario nocturno, o Plusvalía (1995-97) que acaba cuando el canal pasa a ser en abierto y convertirse en Cuatro; y en Tele 5, Noticias y Negocios (1995-96), o más tarde, Mi Cartera, que se emitía los sábados a la 1 de la madrugada. Estos programas, a pesar de su escaso éxito, deberían ser considerados como los pioneros de las televisiones especializadas 
en economía. Pocos sobrevivieron o derivaron en microespacios como Avances o Mi Cartera. $\mathrm{CNN}+$, del grupo Prisa, cuenta en su parrilla con varios programas específicos financieros, como Economía 23, dirigido por Alonso Trenado y que se emite todos los días de 23:30 a 00:00 h. T

Salvo estos casos excepcionales, pocas televisiones generalistas se han querido enfrentar al reto de realizar un programa específico de economía. Con la televisión analógica, algunas televisiones locales compran espacios a otra para completar su programación como es el caso de Canal 7 que, mediante un acuerdo con Bloomberg $T V$, en tres ocasiones diarias, emite la programación española del canal financiero. Canal 7 lo utiliza como informativo pero, claro está, tiene un altísimo componente económico, lo cual no se corresponde con el perfil generalista de su público.

Estos programas son testigos indudables del intento, por parte de las televisiones generalistas, de tratar la especialización, aunque el esfuerzo nunca se vea recompensado. Sólo con la aparición de las plataformas digitales y los primeros canales temáticos, hemos podido ver televisiones específicas de economía. El auge del periodismo económico en televisión se alcanza, por tanto, gracias al aumento de la programación y de los contenidos que ofrece la televisión de pago a través de múltiples plataformas digitales o de cable.

Hablamos de la década de los 90. Bloomberg TV se instala en España en 1997. Pocos meses después, y con una estrategia similar, desembarca en España el grupo mexicano Televisa, liderado por el magnate de medios Emilio Azcárraga, que pone en marcha el segundo canal financiero para los españoles. Conexión Financiera, un proyecto que se trunca al año de nacer tras la muerte del propio Azcárraga. El canal fue adquirido por el grupo Recoletos que puso en marcha Expansión TV, objeto de estudio en este artículo. 


\section{Andanzas y avatares de una televisión económica}

El auge del periodismo económico comenzó en España hacia 1985, año a partir del cual, como ya se ha apuntado, las secciones de economía en radio y televisión empezaron a ocupar un lugar destacado en las redacciones, coincidiendo con la llegada de los primeros diarios especializados en la materia. La aparición en 1994 de la especializada Radio Intereconomía supuso una reserva para el sector, sin embargo, la emisora se instalaba en el mercado avalada por las numerosas publicaciones especializadas en economía y finanzas que confirmaban que, en España, los asuntos económicos interesaban, y mucho.

Lo que no estaba tan claro era si entre las audiencias había un hueco para canales similares en televisión. Los profesionales y los empresarios de medios de comunicación conocían, sin duda, la existencia de Bloomberg TV y de Reuters TV (ya desaparecida), pero eran canales, o herramientas, que se integraban en algo mucho más complejo que la puesta en marcha de una televisión. Por otro lado, la legislación española y la adjudicación de licencias era un tema demasiado complejo para intentar un canal temático económico.

La llegada de los cableoperadores y las plataformas digitales en los 90 cambió ese panorama. Nacía la televisión de pago y, con ella, el aumento de las ofertas de contenidos, entre ellos, los económicos. Boomberg TV, que dirigía la división europea desde Londres, se instalaba en España en 1997 como una herramienta del todopoderoso grupo financiero Bloomberg LP. Expansión TV se convierte en la hermana menor del diario del mismo nombre. Recoletos inicia así su aventura televisiva, no sin grandes problemas. Veamos su trayectoria. 


\subsection{Conexión Financiera (1997-1998)}

Cuando apenas Bloomberg TV había iniciado sus emisiones en España, en 1997 aparece un segundo canal financiero que pone en marcha el grupo mexicano Televisa, perteneciente a la familia Azcárraga. Televisa contaba con un canal económico, Conexión Financiera que, desde su sede central en México D.F., transmitía vía satélite a diversos países de influencia latinoamericana. Después de abrir sucursal en Nueva York, Televisa entró en el mercado español, de la mano del periodista J ulio Fernández. Como todos los inicios, los suyos también fueron duros, y especialmente porque coincidieron con la muerte del fundador de Televisa, Emilio Azcárraga Vidaurreta. Problemas con sus herederos y cambios de estrategias, hicieron que el proyecto tuviera muy poca fortuna y terminara fracasando al año y medio de su nacimiento.

\subsection{Expansión TV (1998)}

La herencia de ese equipo en España pasó, en 1998, a manos del grupo Recoletos que, a través de un acuerdo, se quedó con parte del equipo técnico y humano, dirigido en esta ocasión por el periodista Salvador Arancibia, cuyas valoraciones forman parte de las conclusiones de este trabajo. Líderes en la prensa económica gracias al diario Expansión, Recoletos había decidido probar suerte en los medios audiovisuales. Paralelamente a la compra de la televisión, obtuvo una licencia de radiodifusión para una emisora que llevaría el nombre de la cabecera: Radio Expansión. Con licencia para emitir, con equipos y recursos humanos, el proyecto nunca llegó a ser una realidad.

Tras el acuerdo con Televisa, el canal fue rebautizado como Expansión Financiera y se puede ver a través de Vía Digital. Una tímida programación se completaba, al principio, con el canal mexicano, hasta que el acuerdo terminó y Recoletos se quedó con el cien por cien del canal. Esto ocurría en marzo de 1998, justo un año después 


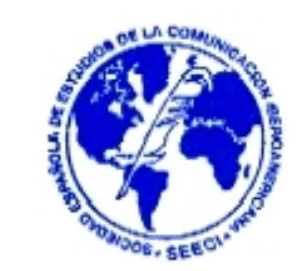

de que Bloomberg empezara a emitir una televisión de 24 horas noticias económicas.

El control de Recoletos se dejó sentir desde el principio en la programación. Los contenidos seguían siendo económicos pero mucho más centrados en el mercado español, en detrimento del americano que no interesaba tanto, según la nueva filosofía empresarial. "Lo importante es qué pasa en España y sobre todo en la bolsa española con leves pinceladas de lo que pasa en el resto del mundo sin ejercer ningún magisterio en esos temas", explica el director de informativos Javier Marquina.

Pero el modelo de negocio Expansión TV parece que ha entrado en crisis desde el año pasado (2002). La causa inmediata es la fusión de las dos plataformas digitales. El papel de los suministradores de contenidos, como Expansión TV, ha pasado de tener un papel importante a un papel subordinado. Una de las dos plataformas, Digital +, asumía el coste de subir la señal de Expansión TV al satélite. Con la fusión de ambas, ese acuerdo se ha roto. Por un lado, se introduce un gasto en la cuenta de explotación de Expansión TV muy elevado; y se produce en un momento en el que la publicidad en ese tipo de televisiones no acaba de crecer, a pesar de ser una de los canales temáticos que más publicidad tiene. No da para compensar los incrementos de costes que se han experimentado. Los augurios para este año no parecen mejorar.

\section{Conclusiones}

Una de las conclusiones mas interesantes podría ser la evidencia de lo difícil que resulta mantener un canal especializados en economía. El canal español ha pasado por dos dueños diferentes y aunque aproveche las sinergias de su hermano mayor, Expansión, líder de la prensa económica española, los problemas a los que se enfrenta, a pesar de su proyecto a largo plazo impulsado por las nuevas tecnologías de la información y la comunicación, los problemas económicos a los que se enfrenta 
son temibles.

Antes, debería aludirse a que como especialidad, la información económica sigue siendo una de las mas complejas y difíciles del periodismo. Prueba de ello son las dificultades a los que se han enfrentado algunos programas especializados en las televisiones generalistas y los propios problemas de subsistencia de los canales temáticos que, en su día, apostaron por ofrecer una programación altamente especializada. El leguaje técnico, la especialización que se requiere de los profesionales, los elevados costes de una televisión y la minoritaria audiencia, no justifican la existencia de una canal temático económico, salvo que pertenezca a un grupo consolidado en la especialización, como es el caso de Intereconomía.

Bloomberg TV y Expansión TV son dos canales especializado en economía. El primero, nacido en 1997 pertenece al imperio Bloomberg LP y está configurado como una herramienta para transmitir datos financieros. No importa la audiencia, su público objetivo son las entidades financieras que contratan sus servicios. El canal español, Expansión TV, está haciendo malabarismos para subsistir ya que sí depende del público y de los hogares que consumen su programación.

Sin embargo, la información especializada en economía aparece como una demanda de la audiencia y una necesidad evolutiva de los propios medios. Cada vez más, y siguiendo una tendencia universal, las audiencias se especializan y se definen por sectores. El hecho de que el español medio invierta sus ahorros en la Bolsa, implica una mayor demanda de información económica. Nace un nuevo tipo de audiencia, la interesada en la economía, la que quiere saber más y conocer todos sus entresijos. Desde los pequeños inversores hasta los profesionales de las finanzas, todos quieren, como telespectadores, que la información responda a sus necesidades. La profusión de diferentes plataformas de televisión (satélite, cable y TDT) ha sido un factor desencadenante para la existencia de canales temáticos y, dentro de estos, para los canales especializados en economía. 
Los canales analizados en este trabajo, -con un modus operandi similar y distintos puntos de vista empresarial-, han aprovechado su capacidad expresiva y lingüística para establecer una correcta comunicación en el ámbito de la información económica. La posibilidad de ofrecer gráficos, de poner caras a las noticias económicas y de ofrecer información de los mercados, tanto españoles como internacionales, en tiempo real ofrecen una clara ventaja competitiva frente a otros medios, supliendo así sus carencias estructurales. Se trata de un lenguaje propio que tiende a reducir las cifras y los datos utilizando sinónimos o comparaciones y ayudándose de los avances que hoy permite la infografía, todo ello sin perder el rigor que la materia requiere. Ese lenguaje propio es una peculiaridad de la información económica audiovisual.

Estos nuevos discursos televisivos de la información económica presentan, pues, algunas peculiaridades:

- Un lenguaje más técnico, caracterizado por ir de la información general a la específica, centrándose en analizar la economía desde un punto de vista profesional, donde la información generalista sólo sirve como referente. Un lenguaje que se complementa con tratamientos específicos que incluyen imágenes, gráficos y postproducción propios.

- Un lenguaje que sirve para informar, formar y entretener y captar audiencia.

- Por sus implicaciones políticas, empresariales y sociales, la información económica audiovisual recibe un tratamiento serio, riguroso y divulgativo a pesar del ostracismo que, en ocasiones, presentan las fuentes, el marketing y las relaciones públicas.

- La concepción de la pantalla es diferente a la tradicional. La sobreimpresión de datos o tickers que ofrecen información financiera en tiempo real es una característica fundamental.

- El seguimiento de los mercados bursátiles, nacionales e internacionales, es el pilar de la programación y su razón de ser, al informar en tiempo real de la 
evolución de los valores. De él se deriva el éxito de los consultorios bursátiles y la interactividad de la audiencia que participa pidiendo consejos y recomendaciones tras exponer sus preocupaciones inversionistas.

- Las audiencias definen el modo de hacer en estos canales temáticos: periodismo de intermediación, en el caso de Bloomberg TV, frente al periodismo interpretativo que practica el análisis y la crítica, en el caso de Expansión TV

Apuntados los problemas a los que se enfrenta la información económica en un canal temático, es imprescindible añadir, de cara a futuros análisis, la importancia que están adquiriendo los portales financieros de Internet. I rrumpen con fuerza el periodista multimedia, las ediciones digitales y los nuevos medios que con costes inferiores, son más rentables. Quizá se pueda afirmar que, al menos en España, el desarrollo de la información económica ha tocado techo en cuanto a medios tradicionales (prensa, radio y televisión). Frente a esta visión catastrófica, Internet se ofrece como la vía más factible para asegurar y mantener la información económica ante un público fiel. Portales financieros, diarios económicos digitales y blogs de expertos empiezan a constituirse en la primera fuente de información económica para periodistas y particulares. ¿Hablamos de una nueva etapa de la información económica?

\section{Bibliografía}

BALSEBRE, Armand (1994). El lenguaje radiofónico. Cátedra. Madrid.

CEBRIÁN HERREROS, Mariano (1998). Información Televisiva. Mediaciones, contenidos, expresión y programación. Síntesis .Madrid:

PIEDRAHITA, Manuel (1998). Periodismo impreso, audiovisual y electrónico del siglo $X X I$. Universitas. Madrid. 